\title{
EL CONVENTO DE SAN AGUSTÍN DE LA CIUDAD DE MÉXICO. NOTICIAS SOBRE LA CONSTRUCCIÓN DE LA IGLESIA
}

\author{
Eduardo Báez Macías
}

\begin{abstract}
Este artículo ha sido posible por la benevolencia de Guillermo Tovar de Teresa y Augusto Vallejo. A ellos debo el conocimiento de los documentos que describo. En la tarea de rescatarlos y darlos a conocer, mi parte ha sido la menor.
\end{abstract}

Una de las mayores construcciones que nos dejó el siglo xvil ya finalizando, es el convento de San Agustín, enorme mole de mampostería y cantera echado sobre casi dos manzanas de la ciudad de México. En extensión rivalizaba con el de Santo Domingo y solamente cedía -como cedían todos- ante la enorme mancha que ocupaba la casa de los franciscanos, verdadera ciudad dentro de la de México. Pero, como sucede en otros muchos casos, nuestro conocimiento sobre el convento de San Agustín no corresponde a su grandeza, en cuanto que ignoramos muchas cosas sobre su construcción y las investigaciones en ese sentido han alcanzado sólo magros resultados.

El mejor y más completo estudio que se ha escrito sobre el monasterio se debe a Manuel Romero de Terreros, quien lo publicó hace ya algunos años, en 1950. ${ }^{1}$ Posteriormente se reeditó en 1985. Recoge y analiza las informaciones que los cronistas e historiadores de la capital y de los agustinos han consignado, añadiendo documentos más interesantes como los contratos celebrados por los religiosos con Tomás Xuárez y Salvador Ocampo, maestros ensambladores, para tallar el altar mayor y la sillería del coro, respectivamente. Estos valiosos documentos, agujas de oro en el pajar de la investigación, habían sido descubiertos y publicados por el enorme investigador recientemente desaparecido que fue Enrique Berlin.?

\footnotetext{
${ }^{1}$ Manuel Romero de Terreros, La iglesia y convento de San Agustín (1a edición, 1950), México, Universidad Nacional Autónoma de México, Instituto de Investigaciones Estéticas, 1985.

${ }^{2}$ Heinrich Berlin, "Salvador de Ocampo a Mexican Sculptor", en The Americas, vol. IV, núm. 4, Washington, abril de 1848.
} 
Hace unos años, con motivo de la reparación general que se hizo en el edificio, apareció el libro Antiguo templo de San Agustin. Su restauración, editado con la colaboración del Instituto de Investigaciones Bibliográficas de la Universidad Nacional Autónoma de México. En él se detallan las obras de restauración y se repite la historia de la fundación agustina, con textos de Jaime Emilio Muñoz.

Hoy, merced a la magnanimidad de dos eficientes y esforzados investigadores, que son el licenciado Augusto Vallejo y la maestra Carmen Saucedo, he podido consultar un par de documentos que ellos localizaron, en el Archivo Judicial del Distrito Federal, que arrojan nuevos conocimientos para la verdadera historia del convento de San Agustín, en lo que toca solamente a la construcción de la iglesia y ya superando el nivel de la fastidiosa repetición de los datos que desde muy antiguo se han venido citando.

El primer documento es un libro encuadernado en pergamino, manuscrito en 1569 con el siguiente título:

Libro del depósito de este monesterio de nuestro Padre San Agustín de México, que comienza a primero de junio de 1569 años, que el padre fray Diego de Vertavillo entró por prior de esta casa, y desde dicho día comenzó a recibir y gastar según se sigue, siendo depositarios los padres fray Alonso de Villalpando y fray Jerónimo Meléndez. 1569.

Tenemos entonces un libro en el que se fueron registrando los ingresos que el convento recibía por diferentes conceptos, lo mismo que el destino que daban a esos dineros, que es lo que ahora nos interesa, y que no era otro sino pagar los materiales y la mano de obra con que iban terminando los buenos religiosos la iglesia de su monasterio. Aunque sabemos de antemano, y muy a pesar nuestro, que en estos libros de cargo y data, como en los de fábrica, existe un cierto descuido cuando se hace referencia a los constructores y artistas que tuvieron que ver en la fábrica. Para los padres administradores, el mismo miramiento merecía el carretero en cuyas mulas se transportaban la piedra y la cal, que el pintor cuyo pincel ilustraba un retablo. Todo esto muy explicable porque la razón de llevar estos libros era controlar el dinero, y no exaltar ninguna obra de arte, que esto ya lo dejaban a los poetas y a los apologistas. Qué diéramos nosotros, los que hacemos historia del arte, por que cada monasterio hubiera tenido su fray José de Sigüenza.

En este documento hemos tenido que buscar, renglón a renglón, palabra a palabra, la información precisa que necesitamos. El resultado es un 
grupo de datos, no muy abundantes pero sí valiosos en cuanto a su valor probatorio, que corresponden a lo que podríamos llamar las últimas etapas de la construcción y sus toques finales.

Romero de Terreros ${ }^{3}$ afirma que el monasterio se comenzó el día 28 de agosto de 1541, día de San Agustín, y que el virrey Antonio de Mendoza puso la primera piedra. Agrega que quedó terminado, salvando algunas críticas que atrajo la suntuosidad con que se iba levantando, en el año de 1587 y que, aunque el edificio sufrió algunos hundimientos, quedó la iglesia suntuosísima, cubierta con un alfarje ricamente adornado de casetones y entrelazos de maravilloso artificio. Una armadura adornada con labores de lacería, ni más ni menos.

El documento que estudiamos principia el día 1o. de junio de 1569 , cuando entró como prior fray Diego Vertavillo, y termina en 1587, dieciocho años después. Como las noticias que proporciona se refieren exlusivamente a la enfermería, la sacristía y la "iglesia nueva", debemos deducir que todas las otras dependencias se terminaron antes de 1569. Como era costumbre, hasta el final se dejó a la iglesia, y si ésta es citada como la "iglesia nueva" quiere decir que hubo antes otra, de la que nada sabemos, y que por ser provisional debió ser muy modesta y deslucida.

El padre Vertavillo, en cuyo priorato se inició este libro de cuentas, ya era conocido nuestro por la cita que hace Manuel Toussaint "... y así nos cuenta Grijalva del padre Vertavillo que deseaba para sus templos y conventos que todas las piedras fueran de quilate, es decir, que fueran piedras preciosas". 4

Lo que sería más admirable de esta primera iglesia agustina, aparte de la armadura ya citada y elogiada, sería el retablo del altar mayor. Sus pinturas, afirma Romero de Terreros, ${ }^{5}$ fueron ejecutadas por Andrés de Concha. Guillermo Tovar de Teresa también supone que el retablo es obra de de Concha, basándose en una relación que escribió Dionisio Rivera Flores en 1599. Sólo que Tovar estima que el retablo se haría entre 1590 y 1599. ${ }^{6}$

Pero ahora tenemos que, de acuerdo con lo que quedó asentado en el libro de gastos, no fue de Concha, sino Simón Pereyns, quien hizo las

\footnotetext{
${ }^{3}$ Op cito, p. 6 .

${ }^{4}$ Manuel Toussaint, Arte colonial en México, México, Universidad Nacional Autónoma de México, Instituto de Investigaciones Estéticas, 1983, p. 46.

${ }^{5}$ Op. cit., p. 7 .

${ }^{6}$ Guillermo Tovar de Teresa, Renacimiento en México, México, Secretaría de Asentamientos Humanos y Obras Públicas, 1982, p. 117; apud Dionisio Rivera Flores. Relación historiada de las exequias funerales de la Magestad del Rey D. Phillipo II por el Dr... en la casa de Pedro Balli, México, 1600 .
} 
pinturas para el retablo. En la cuenta correspondiente al mes de octubre de 1569 se registra un pago de setenta pesos a un entallador - no da el nombre- por la madera y factura de " "... el banco para el altar mayor, que llaman peana...", así como de otra suma que se dio el mismo día "....a este mismo entallador, para principio de pago de los dos altares colaterales, a cuenta de madera y hechura..."

El nombre de este maestro que hizo el retablo principal e inició los colaterales se nos queda oculto, merced al desgano del escribiente para asentar otros datos que no fueran reales y tomines. Pero más abajo, en la cuenta del mes de diciembre del mismo año, principia a redimirse al asentar en el gasto respectivo: "Dimos a Symón, pintor, quince pesos para en cuenta de pago de treinta pesos que se le da por pintar las imágenes del retablo del altar mayor de la iglesia nueva."

Y suma, con el mismo desenfado, otros treinta pesos entregados al "entallador que hace los retablos colaterales de la iglesia nueva... para en cuenta de pago de lo que se le da, que son cien pesos...."

El pintor "Symón", tacañamente citado, no es otro que Simón Pereyns, que tres años antes arribara a la Nueva España en la comitiva del virrey don Gastón de Peralta. El entallador corrió con menos suerte y se quedó fuera de la historia.

Dos meses después, en febrero de 1570, se repite más o menos lo mismo: "Y dimos al pintor Symón quince pesos con que se acabó de pagar las tres imágenes que pintó para el banco y el altar mayor de la iglesia nueva".

Pasan casi dos años sin que se diga algo relacionado con los altares, aunque no falta alguna cosa de cierto interés como el pago de unos aldabones para la casa del órgano "...que hizo Francisco del Castillo".

Para septiembre de 1571 se dice que estaban terminados los colaterales, pero tampoco en esta ocasión se nombra al contratista, sino únicamente a un oficial llamado Guillermo: "...diéronse para acabar de pagar los retablos colaterales de la iglesia nueva, de madera y manos, noventa pesos, con los cuales se acabó de pagar al oficial Guillermo. Costaron todos de madera y manos ciento ochenta pesos".

Suponemos que hasta aquí estaban terminados los retablos en lo que toca a su talla y ensamblado, porque unas líneas más abajo se hace mención de un maestro pintor que se encargaría de pintarlos:

Yten. Mas nos concertamos en Pedro Rodríguez, pintor, para que pinte y dore y estofe, y en fin los ponga en perfición, los dos altares colaterales a vista de oficiales. Igualámoslo todo en seiscientos cincuenta pesos, a los de dar acabados para navidad. 
Volvemos a consultar a Toussaint y encontramos que hubo un Pedro Rodríguez, pintor, que fue veedor de pintura en $1585 .{ }^{7} \mathrm{La}$ poca diferencia de fechas induce a pensar que se trata del mismo artista.

Lo desconcertante del documento es que se diera al pintor un plazo tan corto para poner en perfección los dos colaterales. ¿Qué es lo que exactamente se obligaría a hacer en sólo tres meses? No parece posible que se comprometiera a pintar, dorar y estofar un par de altares que seguramente no serían pequeños, si se encargaban para la iglesia del convento principal de la orden. Quién sabe que es lo que pudo haber hecho este Rodríguez en el plazo convenido, pero desde luego que no terminó. En enero de 1572 se encuentra esta anotación: "Dimos a Pedro Rodríguez para en cuenta de los retablos que pinta para la iglesia cincuenta pesos."

Pero no vuelve a mencionarse pago alguno. Si Rodríguez abandonó el trabajo no podemos saberlo, pero parece cierto que no terminó los retablos y que éstos quedaron suspendidos durante varios meses

Más adelante, en las cuentas de septiembre de 1572, anotando los pesos y reales gastados para comprar tocinos, garbanzos y lentejas, el hermano administrador anotó lo siguiente: "Se pagaron a Zumaya, pintor, por lo que pintó y doró en los altares colaterales, cincuenta pesos."

Fue Francisco Zumaya, el otro miembro de la trilogía formada por Pereyns y Concha, quien terminó los colaterales. El hecho de que se diga pintó, en pasado, indica que en el momento de recibir el pago los tenía acabados, aunque seis años más tarde se le hizo otro pago de cuarenta pesos: "Dimos a Zumaya en cuenta de unos retablos que hace, cuarenta pesos."

Pago que volvió a verificarse en abril de 1579, por unos pesos "...que se dieron a Zumaya para los retablos".

Creo que estos últimos pagos ya no se refieren a los colaterales, sino a otros retablos que bien pudieron estar en la iglesia o en alguna otra parte del convento, tal vez en la sacristía quie se concluyó -como se desprende del mismo libro de cuentas- en febrero de 1579, o bien en el refectorio según se desprende de una anotación del mes de diciembre de 1581 que dice: "Ciento veintitres pesos y cinco tomines y seis granos pagados al padre obrero, los ochenta pesos que los pagó a Zumaya de las imágenes del refectorio".

Existe otra anotación en el mes de octubre del año de 1581, de ciento cincuenta pesos que se pagaron por la compra de "seis retablos grandes" para la sacristía y el refectorio. Parece entonces que los retablos en estas

\footnotetext{
${ }^{7}$ Manuel Toussaint, Pintura colonial en México, México, Universidad Nacional Autónoma de México, Instituto de Investigaciones Estéticas, 1965, p. 37.
} 
oficinas se compraron hechos y se colocaron, quedando únicamente por hacerse las pinturas que serían las que se encargaron a Zumaya.

Entretanto, paralelamente a la factura de los retablos, el libro de cuentas nos proporciona otros datos sobre la construcción del convento, por ejemplo, de lo que el padre obrero declaró que llevaba gastado, hasta septiembre de 1575, en la "obra del arco". Como en otros renglones a este mismo arco le llaman "pasadizo", deduzco que se trata del famoso arco que comunicaba, cabalgando sobre la calle, la manzana ocupada por el monasterio con la manzana vecina en que los agustinos habían instalado el noviciado. Coinciden estos datos con Romero de Terreros, ${ }^{8}$ quien afirma que la licencia otorgada a los agustinos, para la construcción del arco, fue acordada por el cabildo previa aprobación de fecha 8 de julio de 1575 del virrey Martín Enríquez. La única condición fue que el arco o pasadizo tuviera cuando menos dos pisos de alto para que no estorbara el tránsito de la calle.

Se habla también de la liquidación a un tal Simón Buenaventura, fundidor y maestro campanero, por la entrega de la campana grande que pesó cuarenta y dos quintales y dos arrobas (unos ciento quince kilos), y de unas "tablas de plata" que el maestro platero Juan de Torres fundió para los colaterales en 1583. Llevaban dichas tablas una inscripción.

Otro pintor que surge entre estas muy escuetas noticias es un tal Illescas. Manuel Toussaint presenta a un Juan de Illescas, pintor y dorador, que fue nombrado veedor del gremio en el año de $1556 .{ }^{\circ}$ En el Hospital de Jesús, un Nicolás de Illescas fue el autor de la armadura de la sacristía, según contrato que hizo con el administrador del Hospital en el año $1578 .^{10}$ Por la cercanía de las fechas, es más probable que sea el segundo el que trabajó en la iglesia de San Agustín. Y, de todas maneras, nos encontramos con una de las primeras dinastías de pintores-doradores de la colonia.

La primera cita de Illescas en el de San Agustín data del mes de marzo de 1581: "Iten Sesenta y siete pesos cuatro tomines que se gastaron en la sacristía, con treinta y dos pesos quesse pagaron a lllescas, de cosas para el monumento."

La segunda cita, de abril del mismo año, dice: "Pagamos a Illescas, pintor, cincuenta pesos de resto de la obra."

La suma total de ochenta y dos pesos que recibió este artífice es bastante elevada, lo que percibiría cualquier otro por ensamblar, dorar o pintar un

${ }^{8}$ Op. cit., p. $9-10$

${ }^{9}$ Manuel Toussaint, op cit. p. 37

${ }^{10}$ Eduardo Báez Macías, El edificio del Hospital de Jesús, México, Universidad Nacional Autónoma de México, Instituto de Investigaciones Estéticas, 1982, p 99. 
retablo mediano; pero solamente se habla de un "monumento", de tal suerte que volvemos a quedar en la incertidumbre en lo que respecta al trabajo de Illescas en San Agustín.

Podemos decir, resumiendo, que el retablo principal fue obra, cuando menos algunas de las tablas, de Simón Pereyns, el gran pintor flamenco que las pintó apenas un año después de su famoso proceso de la Inquisición. Que los colaterales fueron comenzados por Pedro Rodríguez, de quien sabemos muy poco, y concluidos por Francisco Zumaya, el pintor vascongado. Y que la participación de Andrés de Concha, para ser cierta, requeriría una prueba mejor que la frágil afirmación del doctor Dionisio Rivera Flores. Todavía hemos cosechado, de los últimos registros del documento, tres datos importantes:

Uno que confirma la participación de Pereyns, aunque mediando varios años de diferencia con las anteriores noticias, porque ya corresponde a la cuenta de mayo de 1585. Siendo tardío, podría referirse a otro retablo o al mismo principal, si pensamos que bien pudo quedar suspendido durante algunos años; pero el pago esta vez se le hizo por un trabajo de dorado y no de pintura. En todo caso, aunque no es un dato preciso, sí nos confirma la mano del flamenco en esta iglesia. Dice así: "Yten. Trescientos y veintidos pesos pagados a Simón Perins que se le debía de resto de lo dorado... el rector de San Pablo." 11

El segundo dato es un pago efectuado a Bartolomé Luque:

Yten. Doscientos y cincuenta y nueve pesos y siete tomines pagados a Bartolomé de Luque se le debían de resto de su salario de la obra hasta fin de diciembre de 1584

Bartolomé Luque era carpintero y trabajó en las obras del Hospital de Jesús al lado de Juan Salcedo Espinoza, el gran carpintero de lo blanco. Él fue el autor de la cubierta de la iglesia de San Agustín.

Ya Marco Dorta ${ }^{12}$ había descubierto la presencia de Bartolomé Luque en el templo agustino, y nada menos que al lado de Claudio de Arciniega. La conocida amistad que hubo entre este arquitecto y el pintor Pereyns parece haberlos reunido, trabajando juntos en más de una obra. Y en relación con la construcción, no podemos dejar de citar otro dato referido por Kubler, el del inglés Miles Philip que encontrándose cautivo en la

${ }^{11}$ Faltan unas palabras que no pude leer.

${ }^{12}$ Enrique Marco Dorta, Fuentes para la historia del arte hispanoamericano, Sevilla, Escuela de estudios hispanoamericanos, 1951, vol. 1, p 121-125; también en Antonio Rubial García, El convento agustino y la sociedad novohispana, México, Universidad Nacional Autónoma de México, Instituto de Investigaciones Históricas, 1989, p. 229. 
Nueva España distraía su cautiverio supervisando a los peones y canteros que laboraban en la obra. ${ }^{13}$

El tercer dato se refiere nada menos que al escultor Adrián Suster, llegado a México en 1573 y que en esos años trabajaba en el coro de la catedral vieja de México. ${ }^{14}$

Dice el documento: "Yten. Treinta y un pesos pagados a Adriano Soster, que se le deben a la obra."

Volvemos a preguntarnos, tratando de este artista flamenco, si la obra a la que se refiere el texto sería el coro de la iglesia; nada difícil, pues Suster hizo también el coro de Santo Domingo.

Esta joya del manierismo y el mudéjar novohispano, cuyo cuerpo lucía la imprimatura del genio de Pereyns, Zumaya, Suster, Arciniega y tal vez Concha, pereció trágicamente abrasada la noche del 11 de diciembre de 1676. Tres horas tardó en incendiarse la cubierta y tres días en apagarse el fuego. El templo, con su magnífico artesonado y sus retablos, quedó reducido a piedras calcinarlas y ceniza. Imaginemos aquella noche trágica de diciembre, vísperas de la fiesta de la Virgen de Guadalupe. A las siete se prendió el fuego en algún altar de la nave. Las maderas de los altares, las pinturas y la armadura de la cubierta fueron copioso combustible para las llamas. Era una época en la que nada se podía hacer para sofocar un incendio, si no era esperar a que él mismo se extinguiera en acabándose los materiales qué consumir. Esa noche la gente se arremolinó al llamado de las campanas de las iglesias vecinas, acudieron el virrey, la Audiencia, el cabildo y los vecinos notables, Jesús Nazareno y una legión de imágenes, pero a despecho de tan notable asamblea el fuego acabó con todo cuanto encontró en la iglesia. De entre la multitud curiosa y asustada se adelantó una figura, el capitán Juan de Chavarria, quien sin muchas vacilaciones y ante el pavor de la muchedumbre se metió decidido por la puerta del templo. Loco valeroso que pasado un tiempo reapareció entre las llamas, medio chamuscado y como alma vomitada del infierno, llevando en las manos el Santísimo Sacramento que había rescatado del altar principal. Era un hombre valiente, porque se necesita valor para lanzarse a correr veinte o treinta varas entre llamaradas, leños ardientes, escombros y gotas de plomo derretido que llovían de la armadura Era valiente, sí, pero miope; porque cuánto más le hubiéramos agradecido y admirado si, en lugar de coger la custodia -que iguales las había en todas las iglesias- hubiera salvado siquiera una pintura de Pereyns.

${ }^{13}$ George Kubler, Arquitectura mexicana del siglo XVI, México, Fondo de Cultura Económica, 1983, p. 129

${ }^{14}$ Manuel Toussaint, Arte colonial .... p. 81 
El segundo documento es, como el anterior, un libro manuscrito y encuadernado en pergamino, con 245 fojas numeradas, aunque solamente se encuentra escrito hasta la 156. Lo restante quedó en blanco.

En la pasta dice: "Libro de gasto de la fábrica de la iglesia del convento de nuestro padre san Agustín de México."

En la primera plana especifica que el libro se inició el 1o. de julio de 1679, por mandato del padre fray Juan Ponce, provincial de la Provincia del Santísimo Nombre de Jesús de la Nueva España, y que en él se recoge todo el gasto perteneciente a la fábrica de la iglesia del convento de San Agustín de México.

Se trata entonces de un libro de fábrica, pero no es completo y únicamente comprende los años 1679 a 1692 . Romero de Terreros, apoyándose en el Diario de sucesos notables de Antonio Robles señala el 22 de mayo de 1677 como la fecha en que se inició la reconstrucción de la iglesia. Ese día -dice- el virrey colocó la primera piedra. Luego debió existir otro libro de fábrica anterior en el que debieron registrarse los gastos de mano de obra y materiales entre mayo de 1677 y junio de 1678. Los agustinos eran muy meticulosos para administrar su dinero. De existir ese primer libro podríamos saber con certeza quién fue el arquitecto que trazó los planos y principió la obra. Diego Angulo Íñiguez sostiene que fue fray Diego de Valverde, religioso de la misma orden, pero no cita la fuente de su afirmación ${ }^{15}$. Lo que nosotros podemos constatar con la lectura de nuestro documento es que fray Diego de Valverde, junto con fray Bartolomé Guerrero, fray Pedro Pérez de Torrubia, fray Nicolás Carmelo y fray Juan Blanquete, administraban la entrada de dinero y el gasto de materiales para la obra hasta agosto de 1679. Después de esta fecha no se le vuelve a citar; a Blanquete y a Carmelo sí, porque corría a su cargo el abastecimiento de piedra dura y tezontle que extraían de sus propias canteras. Nunca, a lo largo de todo el manuscrito, dejaron de registrar el gasto del chocolate que suministraban al "padre obrero", pero jamás -y esto es exasperanteproporcionan el nombre. Lo de "padre obrero" casa bien con fray Diego de Valverde, pero aún necesitamos un documento más firme.

Pergeñemos ahora entre las páginas de nuestro manuscrito.

En 1679 el edificio se encontraba bastante avanzado porque en el mes de agosto se hizo pago al "padre obrero" para satisfacer los jornales de los que trabajaban en el cerramiento de la bóveda "Otra inscripción interesante, correspondiente al mes de noviembre del mismo año, nos indica que el p. 13

${ }_{15}^{15}$ Diego Angulo Íñiguez, Historia del arte hispanoamericano, tomo Il, Salvat Editores, 1949, 
padre obrero recibió doscientos pesos para entregar “.... Joseph de Aguilera, a cuenta de mil novecientos pesos en que está concertada toda la cantería que falta por labrar en la capilla mayor y sacristía, hasta ponerla en la altura que hoy tiene el cuerpo de la iglesia".

Concluimos que la iglesia empezó a cerrarse en los tramos próximos a la portada, mientras que se atrasaba el trabajo en la capilla mayor cuyos muros alcanzaban entonces menor altura. José Aguilera es el primer nombre de arquitecto, alarife o cantero que brota de las cuentas.

El herrero de las obras era Jerónimo de la Peña. El padre Carmelo proveía la piedra de la cantera de los Remedios y el hermano Blanquete el tezontle que sacaban de Santa Martha.

En 1680 Aguilera continuaba al frente de la cantería. Recibió ochenta pesos por la puerta de la capilla de "Totolapan" y ciento cuarenta más por el destajo en la capilla mayor. Se seguía trabajando en el cerramiento de las naves, pues aparece una cantidad fuerte, doscientos pesos, por "la madera para las cimbrias de las bóvedas", aunque algunas ya estuvieran concluidas, según se infiere de un pago al herrero "por los cañones de plomo para las bóvedas". Estos cerramientos deben referirse a las naves laterales.

De 1681 hay pocas noticias. Los religiosos siguieron trabajando y soportando algunas críticas porque la construcción iba muy suntuosa, de lo que ellos mismos se resintieron porque además de sus ingresos ordinarios hubieron de salir a pedir limosna por las calles de la ciudad y en la puerta misma del monasterio. No faltaron benefactores que asumieran el compromiso de cubrir cierto número de jornales, pues ni a éstos citan los administradores.

El año siguiente, 1682, se inicia con una noticia importante que nos dice que el día 19 de enero "...se le entregaron al dicho padre obrero otros treinta pesos en los cuales concertó el maestro Pedro de Medina el retundido y aderezo de la historia de nuestro padre San Agustín con Blas de Santa María, para que se le vayan pagando como lo fuese haciendo".

Supongo que se trata del relieve de la portada principal, aunque no sea propiamente una historia del santo obispo, sino un patrocinio y una victoria de Agustín sobre los heresiarcas cuyas cabezas, cubiertas con turbante, aluden a Averroes $y_{1}$ Avicena, o a algunos de sus discípulos, como Siger de Brabante y Boecio de Dacia, que encabezaron la corriente heterodoxa de los "averroístas latinos".

Refuerza mi suposición otra anotación correspondiente al día 24 del mes de septiembre del mismo año. 
...se le dieron al cantero Joseph de Aguilera ciento y setenta y ocho pesos, los ciento de suplemento de nuestro padre provincial a cuenta de el destajo en que va corriendo. Los cuarenta y ocho por las medias muestras de los dos costados de el crucero que pegan al cuerpo de la iglesia, desde el piso de las capillas hasta el capitel. Y los treinta por el

embasamiento de el segundo cuerpo de la portada principal, que todas tres partidas montan la dicha cantidad.

El relieve de San Agustín, que retundió "el maestro Pedro de Medina" se preparó para quedar colocado en el segundo cuerpo de la fachada que iba levantando el cantero, José de Aguilera. Éste, además, labró en el mismo año las medias muestras para los soportes del crucero.

En 1683 se empezó a pagar a los carpinteros Diego de Mendoza y Pedro de Avendaño, pero no se especifica en qué trabajaron. Hasta ese momento, la nómina se concretaba al herrero, a los peones y a los oficiales "silladores". Como las cuentas se llevaban por semana, leemos que en cada una se pagaban treinta y cuatro pesos y tres reales de jornales, incluyendo peones y silladores, además de once pesos y siete reales que costaba su comida.

A José de Aguilera se le pagaron en febrero treinta y cinco pesos, por "...la mejora del friso del cuerpo de la iglesia, y queda pagado de todo". Parecería por el párrafo anterior que Aguilera obtuvo el pago por haber terminado el cuerpo de la iglesia, pero no fue así. No conocemos en detalle los términos en que destajó o contrató la obra de cantería, pero la nave -como veremos adelante- estaba sin terminar. De todas manera Aguilera falleció unos días después, según la anotación del día 10 de mayo: "Para los canteros que se les pagó por muerte de Aguilera, la semana que feneció el 30 de abril, once pesos siete reales."

A pesar de la muerte de Aguilera, la construcción no se detuvo. En 1684, además de los silladores y los peones, se contratar on nueve canteros que según su grado de habilidad ganaban diariamente un peso los mejores y dos reales los más inexpertos. ${ }^{16}$

Por más de un año no hay noticias de que se pagara o contratara algún maestro que continuara lo hecho por Aguilera, hasta que en el mes de julio se contrató a Feliciano Cabello. Dice el renglón correspondiente de la semana del 10 al 15 de julio de 1684 :

Hízose destajo con Feliciano Cabello por toda la cantería que pertenece a la capilla mayor, hasta recibir el capitel, ventana y media de las dos que van sobre

${ }^{16}$ Dos de ellos ganaban un peso diario, uno ganaba seis reales, cinco ganaban cinco reales y el último y más inexperto dos reales. 
las capillas de el Christo y de la Concepción, con la talla de ambas, a tenerlo todo acabado por fines de agosto, por doscientos y treinta y tres pesos y seis reales, a cuya cuenta se le dieron esta semana cuarenta y seis pesos".

Feliciano Gabello es un alarife que conocemos porque trabajó en 1710 en la iglesia de San Francisco de México, y aunque entre obra y obra hay veinticinco años de diferencia, bien podría ser que fueran padre e hijo o bien un mismo personaje, buen vividor de años. Al fin y al cabo, hay más de un Cabello en el mismo oficio, como veremos adelante.

Los registros de pagos efectuados a Feliciano aparecen únicamente hasta el 26 de agosto siguiente: “... se le dieron a Feliciano Cabello diez y siete pesos con que se le acabaron de pagar los doscientos y treinta y tres en que destajó la cantería de la capilla mayor, hasta recibir el capitel”.

Con ésta y otras anotaciones, más el breve tiempo que trabajó para el convento, podemos deducir que Cabello recibió la obra muy avanzada, limitándose a concluir la cantería de la capilla mayor "hasta recibir el capitel", es decir, hasta dejarla en alberca o encadenada.

Se registran trabajos complementarios, como las rejas para las dos ventanas ochavadas de la capilla mayor, que hizo el herrero Antonio de la Peña. Cada una pesó poco más de seis arrobas y le fueron pagadas a veintiocho pesos, poco más o menos, según el peso. Una de las ventanas quedaba encima de la puerta "de la de Totolapan". Varias veces, en el curso del manuscrito, se hace referencia a la capilla del Cristo de Totolapan. Manuel Rivera Cambas relata que existió en el convento un crucifijo, con capilla especial, venerado como el "Santo Cristo de Totolapan", ${ }^{17}$ y que esta imagen llegó a San Agustín por donación de una indígena que la había comprado en el pueblo de Totolapan, hoy en el estado de Morelos.

Todavía se trabajó en la fachada, porque hay noticias de un tablón que se compró "para cinchas a las columnas de el segundo cuerpo de la portada principal".

En 1685 parece que hubo una disminución en el ritmo de la obra, porque las cantidades erogadas solamente se aplicaron a terminar detalles de lo que hasta ese momento estaba levantado. A Tomás Cabello, seguramente pariente de Feliciano, se le contrató para que labrara veinticuatro piedras para un marco (no especifica cuál) por el que se le pagaron treinta y cuatro pesos. Se compró una arroba de fierro para hacer grapas que se necesitaban en los arcos del coro; se compraron cuatro docenas de reatas

\footnotetext{
${ }^{17}$ Manuel Rivera Cambas, México pintoresco, artístico y monumental, México, Editora Nacional, 1882, tomo II, p. 219 .
} 
para "levantar los pies derechos de la portada" y se pagaron dieciocho pesos por el labrado de seis piedras "de la cornisa grande", a tres pesos cada una. En la fachada, en el mes de abril se pagaron cuatro pesos a un tal Francisco Alberto "por el dorado de la pluma de nuestro padre San Agustín, que se puso en la portada". Resulta muy explicable que haya desaparecido la pluma de la diestra de San Agustín, como podemos verlo ahora. Si en lugar de dorarla la hubieran dejado de cantera, ninguna mano impía se hubiera atrevido a robarla. En este mismo año se trabajó la portada lateral que ve al poniente y que quedó consagrada a la Virgen de Guadalupe, aunque en los asientos de cuentas la llaman la puerta de "Yslaba". ${ }^{18}$ Tratando del gasto de cinco reales se dice: "De copal para remendar las imágenes que se pusieron en la portada tres reales, y dos reales de una imagen de papel de Guadalupe para trassumptar la que se ha de poner en la portada de Yslaba, hacen cinco reales."

Y con otro cantero, de nombre Pedro Ruiz, se destajaron, de la principal, "...las dos conchas de los nichos del segundo cuerpo de la por tada".

Las cuentas de 1686 proporcionan poca información, lo que induce a pensar que se adelantó poco en el gran templo. Se dice que se "embisagró" la Virgen de Guadalupe, que se hizo destajo con el cantero Nicolás Vázquez para que labrara una esquina de la cornisa mayor, contra el pago de doce pesos, y que se hizo trato con Antonio de Eslava para que pusiera dentro de la fábrica, por siete pesos que se le pagaron, los bimbaletes de veinticuatro varas, más otros que puso de hasta veintisiete y veintiocho varas, que costaron a treinta pesos.

Sería por este Eslava que a la portada lateral le daban el mismo nombre. En cuanto al uso de bimbaletes de tan grandes dimensiones, debemos pensar que se preparaban para armar los andamios y malacates y empezar la fábrica de la bóveda central.

En efecto, en 1687 empezaron a comprar grandes cantidades de madera para cimbra. "Mas de cuatro vigas de a ocho, a quince reales cada una, 7 pesos y 4 reales. Ocho tablones a once reales cada uno, 11 pesos. $Y$ ocho cuartones de a ocho pesos cada uno, que toda la dicha madera es necesaria para la cimbria del arco de las barandillas y con dos pesos de su acarreado montó todo 28 pesos y 4 reales".

${ }^{18}$ Esta portada desapareció en las modificaciones emprendidas en 1868, cuando se arregló el edificio para que sirviera como biblioteca. Vicente Heredia, que junto con Eleuterio Méndez se hizo cargo de la obra, lo dice en un informe que rindió en 1869: "Se tapó la puerta que daba al poniente, formándole una bóveda y cimiento para la fuente mural que se ha de colocar en este lugar..."Vid. Manuel Payno, Las bibliotecas de México, México, Imp. del Gobierno en Palacio, 1869 , p. 9. Del mismo informe se infiere que el propio San Agustin, en la fachada principal, apenas escapó a sufrir igual suerte que la Guadalupana. 
Al carpintero Diego de Porras se le dio a destajo el trabajo de las conchas para el arco "de las barandillas", mediante el pago de treinta y ocho pesos. Tardó en echar la concha tres semanas, pero al mismo tiempo siete canteros iban labrando la piedra.

El de 1688 es otro año de poca actividad y son muy pocas las noticias relacionadas con la fábrica de la iglesia cuya construcción se iba dilatando. Aparece, por ejemplo, una diferencia notable entre lo gastado en la obra en el trienio de 1679-1682, que fueron 44206 pesos 7 reales, y lo gastado en el trienio de $1685-1688$, que fue solamente 8563 pesos y 4 reales. Para este año de 88 solamente logré extraer la siguiente noticia:

De las comidas y jornales de nueve canteros, al uno que gana a peso se le dieron esta semana nueve pesos y al otro que gana a seis reales se le dieron esta semana siete, porque se tallaron los alcachofares de las segundas pilastras, y los otros siete canteros ganaron a seis reales por día y todos en los cinco días de la semana treinta y un pesos y siete reales

Interesante que se nos diga que se labraron los "alcachofares" de las segundas pilastras; nombre verdaderamente hermoso y sugestivo que no dudo en identificar con las hojas, entre acanto y alcachofas, que se labraron en los frisos. Terminología de canteros, más vivificante y fresca, algo ingenua quizás, pero muy donosa.

En 1689, cuando ya llevaban diez años trabajando en su monumental iglesia y se llegaba a un punto muerto en que parece que todo esfuerzo se estanca, como quien cobra nuevos bríos se decidieron a acelerar la construcción. Lo primero y más importante fue terminar la parte de cantería que aún estaba inconclusa.

Hízose destajo con Juan de Aragón y Pedro Ruiz de acabar todo lo que falta de arquitrabe, friso y cornisa, que falta en la capilla mayor, por setecientos y cincuenta pesos, de los cuales tienen recibidos los treinta y ocho pesos y un real, contenidos en el gasto de canteros en las dos semanas antecedentes. $\mathrm{Y}$ hoy se les dieron los cincuenta y un pesos y seis reales que se sacaran en esta partida, que unos y otros montan ochenta y nueve pesos y seis reales y medio. Los cuales se les deben rebajar de los setecientos cincuenta pesos con que se les quedan a deber seiscientos y setenta pesos y un tomin y medio, los cuales se les han de ir dando por semana en el término de sesenta días de trabajo en que se obligan a acabar dicha obra, teniendo en el taller dieciseis oficiales cuando menos. Mas se le dieron hoy doce pesos a Juan de Aragón, por dieciseis sillares que tenía hechos por su cuenta, a seis reales cada uno 
Juan de Aragón y Pedro Ruiz trabajaron con puntualidad, de la primera semana de mayo a la primera de agosto. Quizás al final tuvieron algún desacuerdo con los administradores agustinos porque optaron, en la última semana, pagarles por día y no por destajo. Las cantidades que semanariamente se les fueron pagando quedaron escrupulosamente anotadas, y gracias a ello sabemos que un sillar puesto en la iglesia costaba cinco reales, lo mismo si era ordinario, que si era de esquina o de los estribos exteriores. Algunos, que eran más chicos, costaban cuatro reales. Labraron además para el arquitrabe, el friso, la cornisa y las ventanas de la misma capilla mayor. Las piedras para arcos y ventanas implicaban más trabajo y se pagaban más caro; según su tamaño, una piedra de arco costaba catorce o doce reales, y una para ventana hasta dieciocho. Cada semana los destajistas ganaban más de sesenta pesos que era una suma muy respetable.

Para 1690 comenzaron finalmente a cerrar la bóveda de la nave mayor. En la nómina, junto a los jornaleros, oficiales silladores y peones, empezaron a pagar andamieros, que por lo visto formaban una especialidad dentro de los alarifes. Y ya en la semana que corrió del 30 de enero al 4 de febrero, se anotó un pago de veintiún pesos por "Catorce bolsores ${ }^{19}$ de arco toral que se han labrado esta semana a destajo, por doce reales cada uno..."

Esta vez sí quedó especificado que se trataba de los arcos torales, es decir de la nave principal. De enero a junio trabajaron intensamente en labrar los volsores y en armar los andamios. Fue tanta la regularidad con que se registraron los jornales que podemos establecer el número casi exacto de volsores o dovelas que se labraron para los arcos torales: cuatrocientos trece. Como cada dovela costaba diez reales podemos establecer que la hechura de los arcos torales costó a los agustinos un total de quinientos dieciséis pesos con dos reales. Todos los gastos restantes de este año se refieren a materiales y mano de obra relacionados con la bóveda: piedras para arcos chicos, formas de arcos, clavos para empalmar planchas, jornales y comida de canteros, silladores, andamieros y una maroma de ochenta varas.

Otros canteros labraban sillares y rodeos para el cubo de la Torre. Antonio de "Islaba", el mozo, entregó tres mil ochenta rajas de leña de a vara de largo y más de una sesma de ancho para la cimbra.

En el mes de diciembre se dice que la gente andaba trabajando "...en la bóveda después de la capilla mayor, primera de el cuerpo de la iglesia".

$Y$ en las últimas anotaciones, cuando se cerraba el año, se inscribió este elocuente párrafo "...no se asientan comidas y jornales porque prosigue la

${ }^{19}$ Bolsor o volsor, del francés voussoir, dovela 
gente trabajando domingo, fiestas y los demás días, hasta acabar la bóveda expresada en la semana antecedente".

Toda la cantería de los arcos torales se hallaba labrada desde junio de 1690 y las cimbras armadas. En el primer semestre de 1691 estuvieron trabajando en la bóveda mayor y en la puerta de la fachada principal.

Para la mampostería de la bóveda, José Morán de León entregó cuarenta y tres mil ladrillos que le pagaron a siete pesos el millar. También se compraron los tablones para armar los "circhones" de las bóvedas.

Las puertas principales se contrataron con el carpintero José de Torre en la suma de tres mil quinientos pesos, desde el mes de marzo, y resulta curioso que hasta fines del año siguiente se le siguieran abonando sumas regulares, lo que indica que esta puerta tardó en acabarse tanto como la bóveda. La madera que utilizaron fue el cedro. Una plancha de diez varas y media costaba alrededor de veinte pesos.

En el mes de mayo, por primera vez, aparece el nombre del maestro ensamblador y escultor Thomás Xuárez, quien recibió un primer pago de treinta pesos a cuenta de un florón para la bóveda del coro. Con otras sumas que cobró posteriormente recibió en total setenta y tres pesos. El día 16 del mismo mes volvió a contratarse con los frailes: "Concertáronse los siete florones de la iglesia, presbiterio y crucero con Thomas Xuárez a doscientos y cincuenta pesos cada uno, y a esta cuenta se le dieron para maderas cincuenta y tres pesos".

De manera que la iglesia tuvo sus florones en cada tramo de la nave, el presbiterio y los brazos del crucero. Doscientos cincuenta pesos es una suma elevada, aun considerando el costo de la madera y el dorado, de donde podemos inferir que dichos florones eran de gran tamaño, como proporcionados al tamaño de las bóvedas y la nave. Baste saber, para confirmarlo, que los siete pernos de fierro que necesitaron para fijarlos pesaron doce arrobas y dieciséis libras, es decir unos veintidós kilogramos cada perno.

Terminada la nave mayor, también se terminó el cimborrio. Romero de Terreros consigna que fue el 18 de agosto, ${ }^{20}$ pero de acuerdo con el libro de fábrica desde el 21 de abril quedaba cerrado, pues en las cuentas aparece que se pagaron cinco pesos a un oficial de nombre Juan Marcos por la pintura y el dorado de las dos barras de fierro de las claves que cruzaban la boca de la linternilla "o cerramiento del cimborrio en su bóveda mayor".

En agosto se iniciaron los trabajos para decorar el extradós del cimborrio. El maestro locero Esteban Gutiérrez Vergara se encargó de preparar

$$
{ }^{20} \text { Op. cit., p. } 9
$$


DOI: http://dx.doi.org/10.22201/iie.18703062e.1992.63.1646

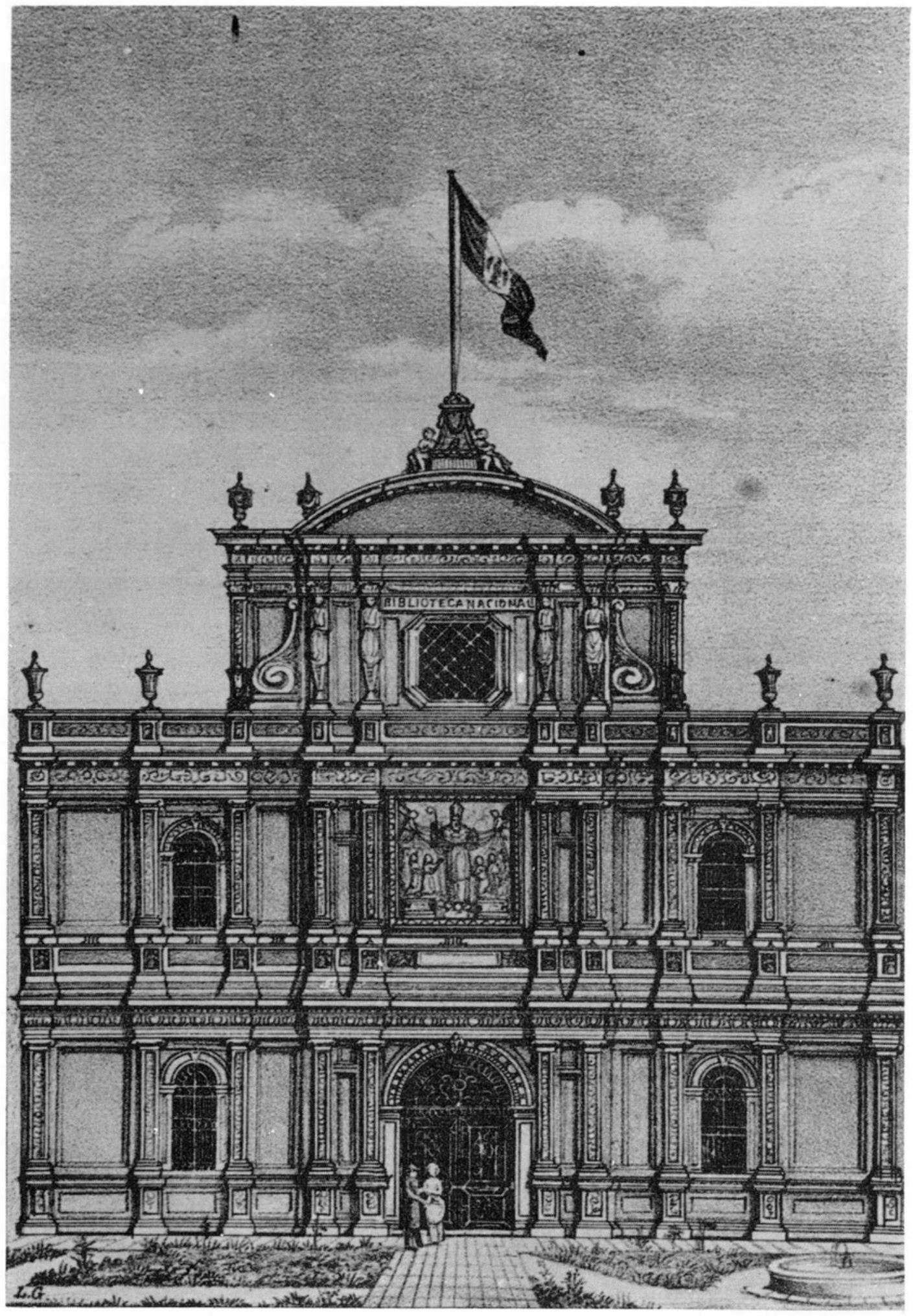

1. Iglesia de San Agustín. Litografía de Murgía. 


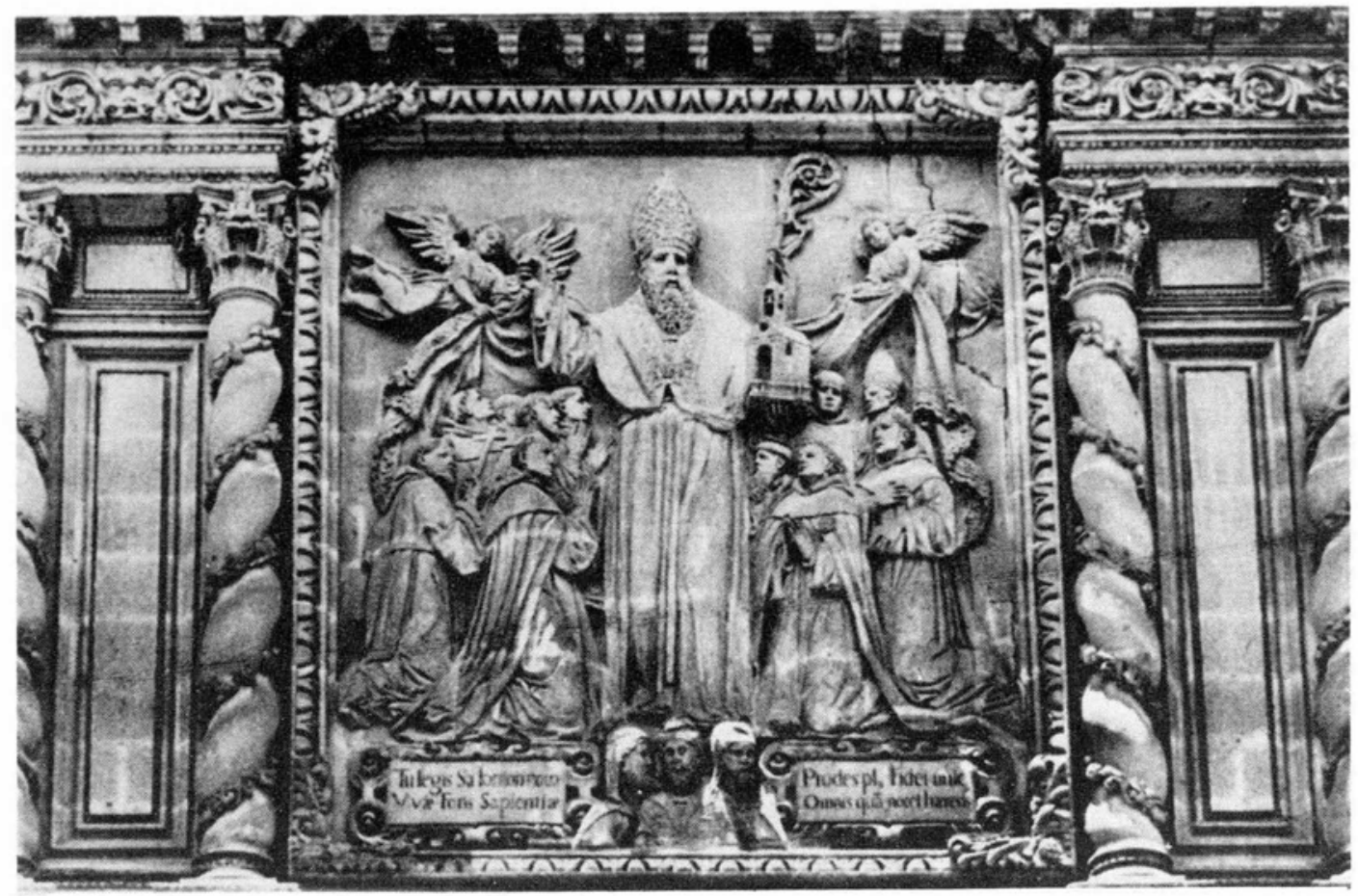

2. “...concertó el maestro Pedro de Medina el retundido y aderezo de la historia de nuestro padre San Agustín, con Blas de Santa María”.

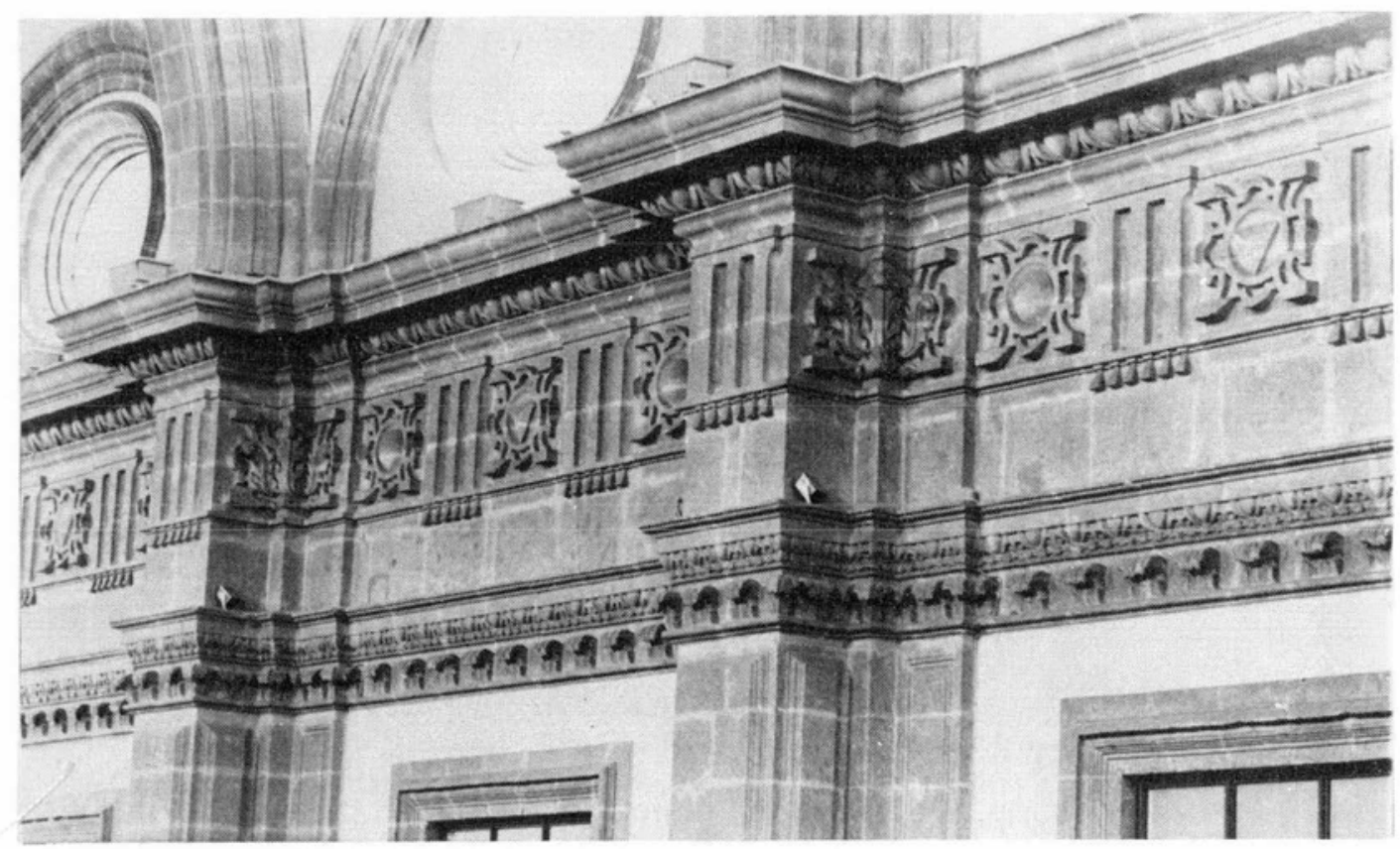

3. “...porque se tallaron los alcachofares de las segundas pilastras..." 


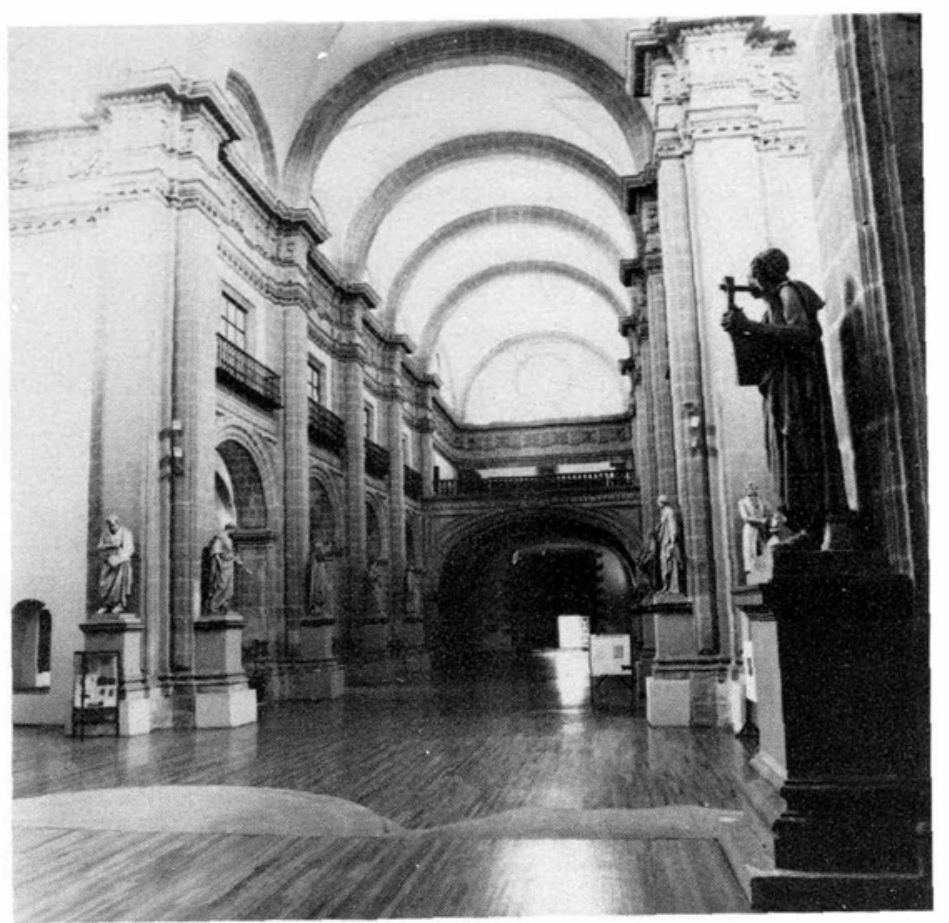

4. “...catorce bolsores de arco toral que se han labrado esta semana... por doce reales cada uno..."

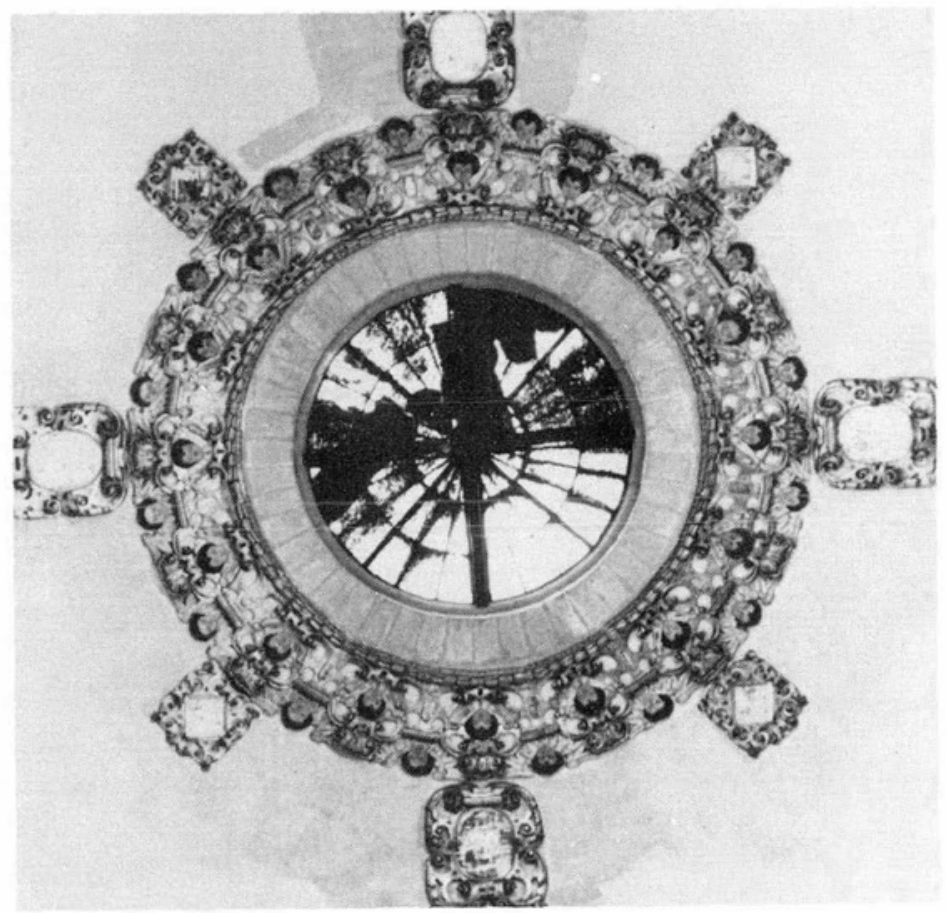

5. “Concertóse con Thomas Xuárez el ensamble...

del anillo que ha de guarnecer por lo interior de el anillo de cantería del cimborrio..." 


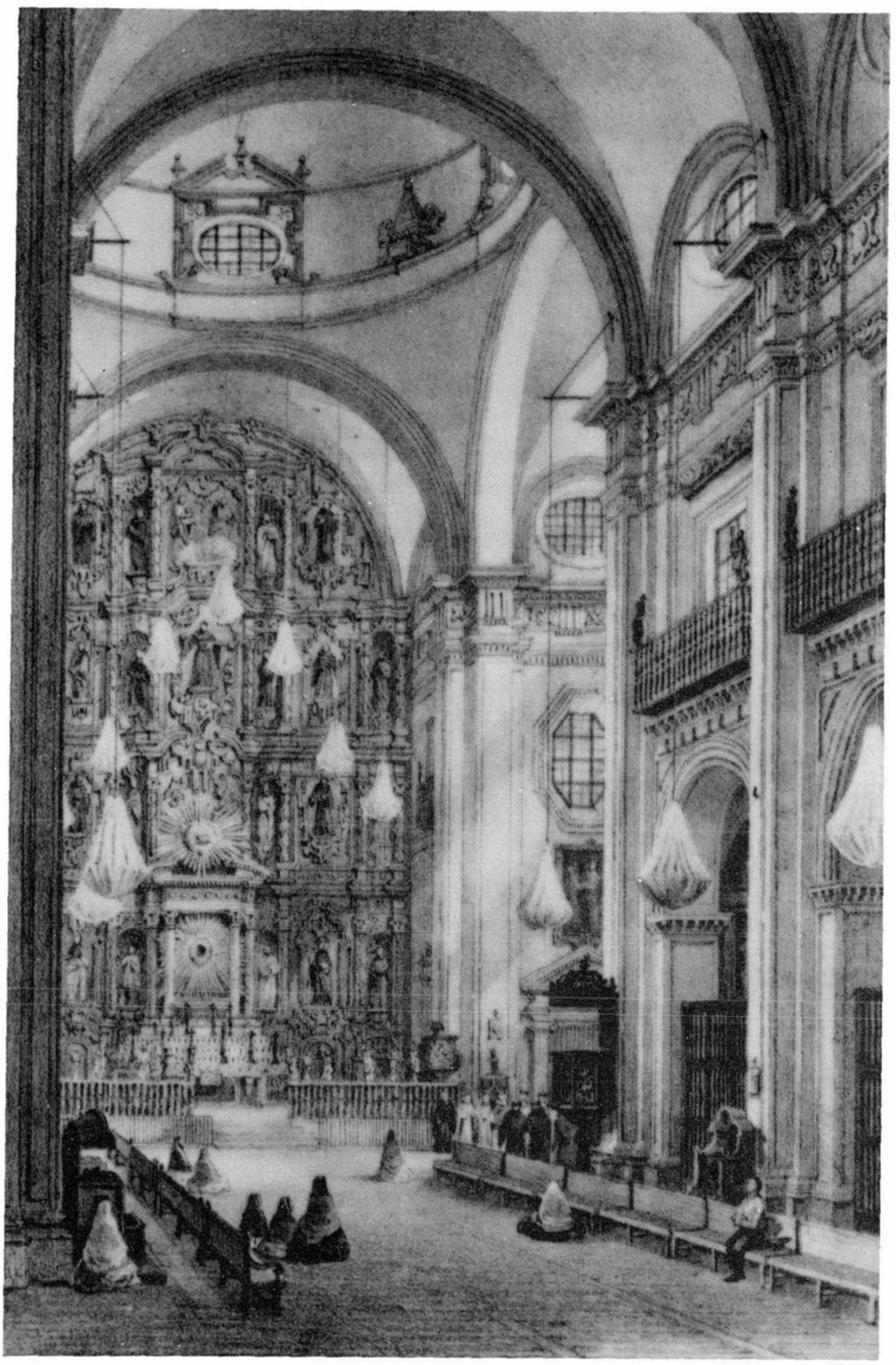

6. “...se pagaron trescientos pesos para el maestro Cristóbal de Villalpando por la pintura de los cuatro tableros del primer cuerpo del retablo". 
los azulejos de barro. Para el mes de octubre tenía entregados en la obra mil novecientos azulejos ordinarios y ochocientos cincuenta azulejos labrados que le pagaran a seis y doce pesos el ciento, respectivamente. Entregó asimismo dieciséis óvalos grandes y negros, a peso cada uno, tres docenas de espejos redondos grandes, tres docenas de espejuelos pequeños y catorce docenas de medianos. En noviembre hizo otra entrega de azulejos amarillos y labrados.

Cerrado el cimborrio procedieron a fabricar la linternilla. La piedra de cantería se contrató con Pedro Ortiz, cantero de los Remedios En el mes de julio entregó catorce carretadas de piedra y en el mes de agosto únicamente doce piedras. Los agustinos tenían su propia cantexa en los Remedios, de donde habían extraído material desde el principio de la construcción, por lo que suponemos que Ortiz solamente se ocupaba de cortarla y entregarla en bruto. El labrado, propiamente, lo hacían en la obra misma.

El cimborrio y la linternilla tuvieron sus remates de barro vidriado que en el libro llaman pirámides. El mismo locero, Esteban Gutiérrez, entregó en octubre ocho pirámides grandes, dieciséis medianas y cuatro pequeñas; en noviembre otras ocho medianas. Todas ellas se fijaron en la cúpula y la linternilla mediante espigas de cedro.

La cruz de fierro que remataba la linternilla se forjó en septiembre y costó cinco pesos.

Hay una partida de ciento quince pesos para comprar unas vigas de cedro que se utilizaron para la baranda del coro y las tribunas. Otra partida de cien pesos pagados a un "maestro Claudio" que hizo la vidriera del coro, $y$ varias sumas pagadas a diferentes canteros que labraron unos setenta escalones de chiluca para las escaleras.

Para finalizar las cuentas de este año de 91 y como si se tratara de otra cosa más, un tablón o un sillar, anotaron lo gastado en un vestido, capa, calzón, gabardina, sombrero y camisa para "el mulato Agustín, esclavo de la fábrica". Al menos lo vestían bien, porque todo ello les costó veintidós pesos con tres reales.

$\mathrm{El}$ año de 1692 es el último que se llevó en las cuentas, porque el 14 de diciembre se inauguró el templo. ${ }^{21}$ Como en toda construcción, quedaban detalles pendientes, pero la obra se dio por concluida para los fines administrativos y el libro de fábrica concluye en la semana del 9 al 12 de diciembre, en la foja 155; las siguientes quedaron en blanco.

En el año de 1692 es un año de mucha actividad, justamente por esa prisa que había en terminar la obra. Aunque la primera noticia, empezando

${ }^{21}$ Ibid. 
el año, se refiere al esclavo Agustín, que se había fugado del convento. Fue hombre libre por seis semanas, hasta que los frailes agustinos pagaron ocho pesos a un ministro de Corte y a un alguacil, que se encargaron de aprehenderlo y regresarlo a la obra. Pero aparte de este curioso episodio tenemos lo siguiente:

Más de cien cargas de tenayuca se recibieron entre enero y mayo para enlosar la lonja.

Más de doscientos escalones de cantera labraron, entre enero y julio, los canteros Juan de Dios, Lorenzo García y Felipe García. Para el presbiterio se labraron las gradas de piedra blanca (a veces le llaman mármol) concertando esta obra con Juan de Aragón y Nicolás de Covarrubias. Dice el documento que la iban labrando a lo largo, pero que viendo que en esta forma dejaban muy escasa huella, determinaron labrarlas a tizón.

Hay noticias de nuevas remesas de azulejos que se utilizaron en el interior de la iglesia, refectorio y sacristía. De las vidrieras que se concertaron con el maestro Miguel Claudio, que eran doce para la capilla mayor, ocho para el cimborrio, dos para el presbiterio y dos para las capillas de la Concepción y Totolapan. Cobró por ellas mil trescientos pesos y existe la constancia de que se trajeron de España mil cien vidrios.

Las campanas San Agustín, San José y Santa Bárbara quedaron terminadas en marzo y pesaron quince quintales ocho libras, catorce quintales tres arrobas y cuatro quintales quince libras, respectivamente.

Cuatro maestros trabajaban para terminar la carpintería: Lucas Rodríguez, José de Roxas, José de la Torre y Joaquín Guerrero. Lucas Rodríguez fue contratado en el mes de enero para que hiciera las seis ventanas grandes de cedro y nogal, encima de las capillas. En junio, para que hiciera la escalera del coro. José de Roxas concertó en febrero el entablado del coro y la librería. Cobró por la mano de obra ciento cuarenta pesos y la madera la proporcionó el mismo convento. Terminó la obra el 29 de marzo. En abril se encargó de la limpieza y aderezo de otras puertas como la "de gracias". En mayo se le contrató para que hiciera tres puertas: "la inmediata a la entrada del coro, la que entra a la torre y la que entra a los fuelles, de obra de tableros de nogal y cedro y media moldura con todos sus herrajes..." En junio todavía colocó la puerta que salía de la sacristía a la capilla del Cristo de Totolapan. Esta puerta se había quitado de la escalera principal y para acomodarla en su nuevo sitio hubo que echarle "prinazos" nuevos y achicar los tableros. Lo más interesante es que Roxas labró en ella a San Agustín y Santa Mónica. Hizo finalmente las puertas del presbiterio y el entablado de la sacristía.

Joaquín Guerrero trabajó en la puerta exterior del coro, hizo los basti- 
dores de la capilla mayor, la ventana de la librería, el entablado de lá capilla mayor, de la sacristía, del crucero, del presbiterio y entrada "de la puerta de Guadalupe hasta topar con el cuerpo de la iglesia".

José de la Torre parece el más importante. En la primera semana de marzo se asentó lo siguiente:

Hizo obligación el maestro carpintero José de la Torre de hacer en el término de cinco meses que comenzaron a correr desde el 20 de febrero de este año de 692: las tribunas y barandillas de el coro con sus antepechos y tableros de nogal y frisos de tapincirán, priñazos y largueces de cedro, canes y telares de lo mismo, por mil trescientos cincuenta pesos....

En junio se hicieron los agujeros en la cantería para meter la solera de las tribunas, y éstas quedaron montadas y terminadas en el mes de julio. Llevaban, visibles bajo el piso, seis floroncillos de oro tallados y dorados por Thomás Xuárez. Debió ser una vista soberbia el poder admirar estas tribunas, volando en el espacio de la nave, con sus florones destellando bajo el piso de cedro.

En abril, se le encargó el entablado de la iglesia “...desde la pilastra del púlpito hasta la puerta principal". En septiembre hizo concierto para "el tor navoz del púlpito, de nogal, cedro y tapincerán..." Finalmente entabló la capilla del Cristo de Totolapan.

Nos queda Tomás Xuárez ensamblador, dorador y escultor "Romero de Terreros publicó el contrato que celebró con los agustinos para hacer el retablo del altar mayor, fechado el 21 de enero de $1697 .{ }^{22}$ Guillermo Tovar de Teresa, historiador fecundo, ha publicado recientemente un volumen que reúne abundante información sobre este escultor y su hijo, el también prolífico artista Salvador de Ocampo, autor de la gran sillería del coro de San Agustín. ${ }^{23}$

Antes de tratar del retablo, diré alguna cosa más de este artífice. Ya lo vimos trabajando los florones para la bóveda desde 1691. El 1o. de marzo de 1692, en la cuenta del gasto se asentó lo siguiente: "Concertóse con Thomás Xuárez el ensamblaje, maderas y alcayatas del anillo que ha de guarnecer por lo interior de el anillo de cantería del cimborrio en doscientos pesos, y a esta cuenta se le dieron cincuenta pesos en primero de marzo".

\footnotetext{
${ }^{22}$ Ibid., p. 37. Romero de Terreros da la referencia equivocada; me hace suponer que no vio los originales sino que los tomó de Enrique Berlin

${ }^{23}$ Guillermo Tovar de Teresa, Los escultores mestizos del barroco novohispano, Tomás Xuárez y Salvador Ocampo, 1673-1724, México, Banca Serfín, S N.C., 1990.
} 
El escultor terminó este anillo en poco más de un mes, y podría ser el mismo que aún podemos admirar en el interior de la cúpula. Luce como un marco de querubines y conchas, todo dorado y policromado; verdadero joyel que engarza el torrente de luz que llega por la linternilla.

Y entrando ya a la fábrica del retablo debemos hacer algunas reflexiones. Las investigaciones de Berlin y Tovar de Teresa nos han permitido conocer el contrato firmado por Xuárez, en 1697, pero en éste quedaba un hueco incómodo, y es que el escultor se obligaba a hacer y acabar "los tres cuerpos que faltan en dicho retablo".

Ahora, con los datos obtenidos en el libro de fábrica, podemos establecer que este retablo se hizo en dos etapas: el primer cuerpo en 1692 y los tres restantes en 1697, que es lo que ya conocíamos.

La primera referencia nos llega de la cuenta del día primero de marzo de 1692: "A Antonio Posadas, por el acarreo de veintidos lumbrales de la madera de ayacahuite que remite don Diego Ruiz Lozano y pertenece a Thomás Xuárez para el retablo, a cinco reales cada lumbral, se le pagaron diez pesos que debe Thomás Xuárez a la fábrica."

Desde el 16 de agosto ya trabajaba la madera, tallando y ensamblando, porque recibió a cuenta sesenta y cuatro pesos; el día 25 siguiente recibió otros ciento cincuenta pesos y el 29 otros ciento veinticinco. En septiembre tuvo dos pagos de ciento ochenta pesos cada uno; en octubre un pago de cien pesos y otro de ciento cincuenta, y en noviembre, cuando terminaba el primer cuerpo, otros mil doscientos pesos. Parece que el día 9 de diciembre se detuvo el trabajo, pagándose los sueldos que se debían a los oficiales ensambladores y doradores.

Existe igualmente la constancia de que a partir del 15 de septiembre se empezó a recibir el oro para el dorado. En esta primera ocasión el maestro José de Sainz entregó cien "libros de oro" al escultor; en octubre, en diversas entregas, un total de quinientos "libros de oro" y en noviembre cuatrocientos más. La última entrega se hizo en diciembre y fue de doscientos once "libros", cuando estaba por detenerse el trabajo. En total, fueron mil doscientos once "libros de oro" por los cuales pagó el convento alrededor de mil doscientos pesos.

Una de las últimas noticias, pero acaso de las más importantes, sale de la cuenta correspondiente al día cuatro de diciembre: "Dicho día se pagaron trescientos pesos para el maestro Cristóbal de Villalpando por la pintura de los cuatro tableros del primer cuerpo del retablo".

Yllegó el día del estreno del templo, que fue el 14 de diciembre de 1692. El retablo principal se encontró terminado en su primer cuerpo, obra de 
Xuárez y Villalpando, el mejor escultor y el mejor pintor de esos años; pero pasada la inauguración se suspendió la obra, durante cinco años, hasta que en 1697 se volvió a contratar al mismo Xuárez para que acabara los tres cuerpos faltantes, conforme a la planta y modelo con que lo había iniciado. Como Villalpando murió en 1714 es probable que también lo hubieran llamado para que pintara los óleos que faltaban. Desafortunadamente, en la conocida litografía del periódico $\mathrm{La}$ Cruz se ven los cuatro cuerpos de este retablo que subiendo desde el piso alcanzaba hasta la rosca del arco, pero no se aprecian detalles.

Aquí termina el libro de fábrica y no queda sino apuntar la postrer noticia contenida en los últimos renglones de la última página. El mulato Agustín, aquel esclavo de la fábrica huido, capturado y vuelto al monasterio, terminó vendido en trescientos pesos. Quizás porque resultaba, en su empeño por vivir libre, un elemento perturbador para los religiosos. 